\title{
Detection and interpretation of clouds types using visible and
}

\section{infrared satellite images}

\author{
Nawal K. Ghazal ${ }^{1}$ and Mustafa J. Shahbaz ${ }^{2}$ \\ ${ }^{1}$ Department of Remote Sensing, Collage of Science, University of Baghdad \\ ${ }^{2}$ Department of Physics, Collage of Science, University of Baghdad \\ E-mail: Nawalk.ghazal@sc.uobaghdad.edu.iq
}

\begin{abstract}
One of the most Interesting natural phenomena is clouds that have a very strong effect on the climate, weather and the earth's energy balance. Also clouds consider the key regulator for the average temperature of the plant. In this research monitoring and studying the cloud cover to know the clouds types and whether they are rainy or not rainy using visible and infrared satellite images. In order to interpret and know the types of the clouds visually without using any techniques, by comparing between the brightness and the shape of clouds in the same area for both the visible and infrared satellite images, where the differences in the contrasts of visible image are the albedo differences, while in the infrared images is the temperature differences. The data are taken by (MODIS), (GOES) and (METEOSAT) because these satellites are forecasting in a near lifetime data. The case studied in 24/12/2016 over the area of Iraq.
\end{abstract} Key words

Clouds types, visible images, infrared images, water vapor.

\section{Article info.}

Received: Feb. 2017

Accepted: Apr. 2017

Published: Sep. 2017

$$
\begin{aligned}
& \text { كثف وتفسير انواع الغيوم باستخدام صور الأقمار الصناعية المرئية والحرارية } \\
& \text { نوال خلف غزال } 1 \text { و مصطفى جمال شهباز2 }
\end{aligned}
$$

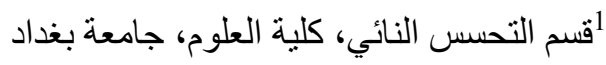

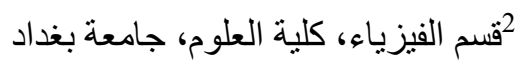

تعتبر الغيوم واحدة من اهم الظواهر الطبيعية التي لها تأثير كبير على المناخ، الطقس و نوازن طاقة التهة الارض.

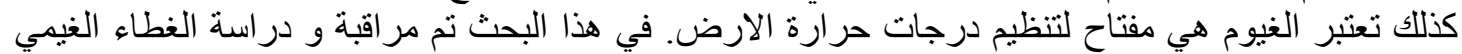

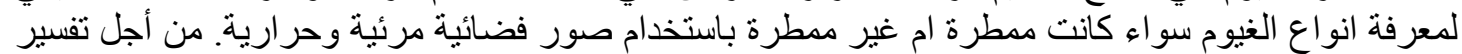

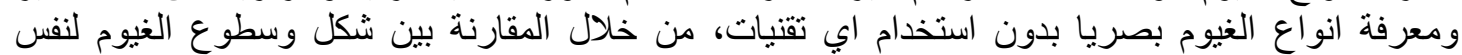

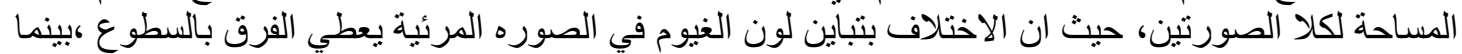

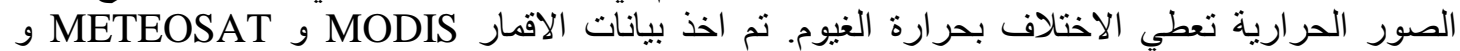

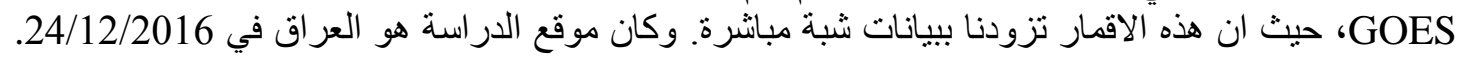

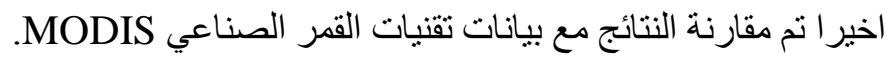

\section{Introduction}

Clouds cover is the amount of clouds that cover the Planetarium, its play an important role in cooling the atmosphere because it reflect the solar radiation and the temperature back to the space and it's the source of rain and snow, so it's one of the important determinants of the climate system, clouds formed when humid air cooled and temperature dropped below its dew point then the water vapor will condense, this Cooling occurs when the air rise to the atmosphere The vapor becomes small water droplets cloud is formed. Clouds are moving 
horizontally and vertically, they don't remain in place where they formed because of the movement of air masses and the direction of wind, which carry the clouds from high pressure to low pressure regions, [1]. Clouds and cloud cover measured by octas unit (1/8 octas), [2], the clouds cover measured either by ground stations or by satellites, satellite can be considered the best way to estimate the cloud cover, taking images for the cloud cover by infrared, visible and water vapor radiation and then sent it to the ground stations for analyses, [3]. In this research used terra satellite, its NASA scientific research satellite, this satellite cares five sensors, the most important sensor is MODIS (Moderate Resolution Imaging Spectroradiometer), A 36-band Spectroradiometer measuring visible and infrared radiation $(0.4-14.5 \mu \mathrm{m}$ with spatial resolutions of $(250 \mathrm{~m}$, $500 \mathrm{~m}, 1 \mathrm{~km}$ at nadir) for derivation of products ranging from land vegetation and ocean chlorophyll fluorescence to cloud and aerosol properties, fire occurrence, snow cover on land, and sea ice in the oceans. GOES satellite (Geostationary Operational Environmental Satellite) it's an
American weather satellite, GOES is an Imager that has five spectral bands. One band is in the visible part of the electro-magnetic satellite spectrum that senses reflected energy while the other four bands capture emitted or infrared energy from the earth. METEOSAT satellite is a geostationary satellite provides visible and infrared images, the first generation of this satellite is meteosat 7, and it is used mainly for weather forecasting.

\section{Data used}

a. TERRA MODIS visible and infrared bands $(0.4-14.5 \mu \mathrm{m})$ with spatial resolutions for visible images are $1 \mathrm{~km}$ at nadir.

b. GOES visible, infrared and water vapor bands $(0.63-13.3 \mu \mathrm{m})$ with low spatial resolution of $4 \mathrm{~km}$ at nadir.

c. METEOSAT 7 visible bands $(0.45-$ $1 \mu \mathrm{m}$ ) with $2.5 \mathrm{~km}$ resolution, thermal bands (10.5-12.5 $\mu \mathrm{m})$ with $5 \mathrm{~km}$ resolution, water vapor bands (5.7$7.1 \mu \mathrm{m}$ ) with $5 \mathrm{~km}$ resolutions.

\section{Methodology of work}

1. Types of clouds

Table 1: The classification of clouds [3].

\begin{tabular}{|lr|c|c|}
\hline Cloud type & & \multicolumn{2}{|c|}{ Classification } \\
\hline High level cloud & $\mathrm{Ci}$ & \multirow{2}{*}{$\begin{array}{c}\text { Stratiform } \\
\text { clouds }\end{array}$} & High level cloud \\
\cline { 1 - 2 } Middle level cloud & $\mathrm{Cm}$ & Middle level cloud \\
\hline Stratus/fog & $\mathrm{St}$ & & Low level clouds \\
\hline Stratocumulus & $\mathrm{Sc}$ & & \\
\cline { 1 - 2 } Cumulus & $\mathrm{Cu}$ & $\begin{array}{c}\text { Convective } \\
\text { clouds }\end{array}$ & \\
\cline { 1 - 2 } $\begin{array}{l}\text { Cumulus } \\
\text { congestus }\end{array}$ & $\mathrm{Cg}$ & & \\
\hline Cumulonimbus & $\mathrm{Cb}$ & & \\
\hline
\end{tabular}

Cloud type classification by satellite imagery, these cloud types are characterized as stratiform clouds $(\mathrm{Ci}$, $\mathrm{Cm}, \mathrm{St})$ or convective clouds $(\mathrm{Cb}, \mathrm{Cg}$, and $\mathrm{Cu}$ ) and the cloud type of Sc has an intermediate character between stratiform and convective clouds.

\section{Clouds classification with heights at troposphere}

Meteorology can be divided clouds into 4 families, which are at different heights of the troposphere: High level clouds (altitudes of 5-13 km), medium level clouds (2-7 km), low level clouds 
(0-2 km) and clouds with large vertical extending (0-13 km) [4].

\section{These clouds families are divided into 10 cloud genus}

a. Low level clouds at heights of (02) km

1-Stratus (st) Made up of very finewater drops occur in the form of rain or spray often depending on the thickness rainfall and seem to form a single layer with a gray base and low clouds are formed by cooling the lower part of the atmosphere as it is often made up of fog rising from the earth's surface [9].

2- Stratocumulus (sc) Cloud plaices, rollers or banks compound dark gray layer cloud. Accompanied by various rainfall intensity and sometimes snowing, formed in many cases from cumulus clouds or cumulonimbus clouds [6].

\section{b. Medium level clouds at heights of} 2-7 km

3- Altocumulus Ac Gray clouds bundles, sheds or rollers, compound like rough fleecy clouds, which are often arranged in banks, shaped by air turbulence or vertical load currents [6]. 4- Altostratus as Dense and gray layer cloud, often evenly and opaquely, which lets the sun shine through only a little [8].

\section{c. High level clouds at heights of 5- $13 \mathrm{~km}$}

5-Cirrus (ci) fibrous, threadlike, white feather clouds of ice crystals, whose form resembles hair curls [5].

6- Cirrocumulus (Cc) Fleecy cloud; Cloud banks of small, white flakes [6]. Formed when saturated air rise by high barrier terrains.

7- cirrostratus Cs Milky, translucent cloud veil of ice crystals, which sometimes causes halo appearances around the moon and the sun [6].

\section{d. Clouds with large vertical extending at heights of $0-13 \mathrm{~km}$}

8- Cumulus $(\mathrm{Cu})$ Heap cloud with flat basis in the middle or lower level, whose vertical development reminds of the form of towers, cauliflower or cotton [7].

9- Cumulonimbus $(\mathrm{Cb})$ in the middle or lower level, developing thundercloud, which mostly up-rises into the upper level, its rainy (shower) clouds [3].

10- Nimbostratus (Ns) Rainy cloud. Grey, dark layer cloud, indistinct outlines [3].

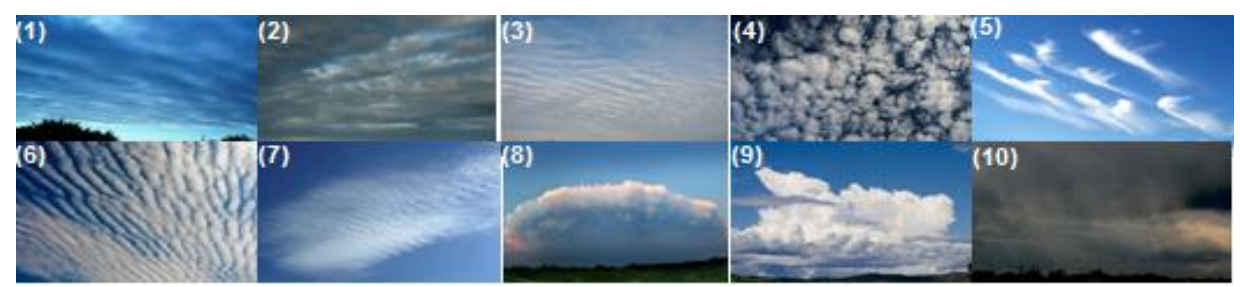

Fig.1: Represents the shapes of clouds as seen from ground, the sequence of images managed, as in the above explanation for the types of clouds [6].

The clouds as they seen from satellite are classified into high, medium and low level cloud. Therefore, it is based on cloud top height, while for meteorological observation is depending on clouds base height, so, for cloud top height, the high level $(\mathrm{Ci}, \mathrm{Cs}, \mathrm{Cc})$ are $400 \mathrm{hPa}$ and above, the middle level (As, Ac) are 400 to $600 \mathrm{hpa}$ while low levels (St, Sc, Ns) 600 hpa or less. In general, $\mathrm{Cg}$ and $\mathrm{Cb}$ are not included in such classifications. While $\mathrm{Cb}, \mathrm{Cg}$ not included in such classification, show Table 2. 
Table 2: The heights and types of clouds [6].

\begin{tabular}{|l|l|l|l|}
\hline CLOUDGROUP & TROPICALREGION & MIDDLELATITUDE REGION & POLAR REGION \\
\hline High & 20,000 to $60,000 \mathrm{ft}$ & 10,000 to $26,000 \mathrm{ft}$ \\
\hline Ci, Cs, CC & $(6000$ to $18,000 \mathrm{~m})$ & 16,000 to $43,000 \mathrm{ft}$ & $(3000$ to $8000 \mathrm{~m})$ \\
\hline Middle & 6500 to $26,000 \mathrm{ft}$ & $(5000$ to $13,000 \mathrm{~m})$ & 6500 to $13,000 \mathrm{ft}$ \\
\hline As, Ac & $(2000$ to $8000 \mathrm{~m})$ & 6,500 to $23,000 \mathrm{ft}$ & $(2000$ to $4000 \mathrm{~m})$ \\
\hline Low & Sfcto $6500 \mathrm{ft}$ & $(2000$ to $7000 \mathrm{~m})$ & Sfcto $6500 \mathrm{ft}$ \\
\hline St, Sc, Ns & $(0$ to $2000 \mathrm{~m})$ & $(0$ to $2000 \mathrm{~m})$ & Sfcto $6500 \mathrm{ft}$ \\
\hline
\end{tabular}

3. Detect clouds by visible and infrared satellite images method 3.1 Detect clouds by visible satellite images

The visible satellite image depends on how much sunlight reflects from the earth and the clouds back again into space. This reflected sunlight from the ground called albedo which has the land range from $10 \%$ to $30 \%$, except for snow the albedo is much higher. The albedo cloud is high and depends on the thickness of it (type of cloud), so the albedo for thin cirrus is low. Most of weather satellite the visible images are black and weight (gray scale images), and for other satellites its true color images (multispectral images), show Table 3 and Fig. 2.

Table 3: The albedo for different surface type [6].

\begin{tabular}{|lc|}
\hline Surface Type & Albedo \\
\hline Large Thunderstorm & $92 \%$ \\
\hline Thick stratocumulus & $68 \%$ \\
\hline Snow & $88-59 \%$ \\
\hline Thin stratus & $42 \%$ \\
\hline Thin cirrostratus & $32 \%$ \\
\hline Forest & $12 \%$ \\
\hline Water & $9 \%$ \\
\hline
\end{tabular}



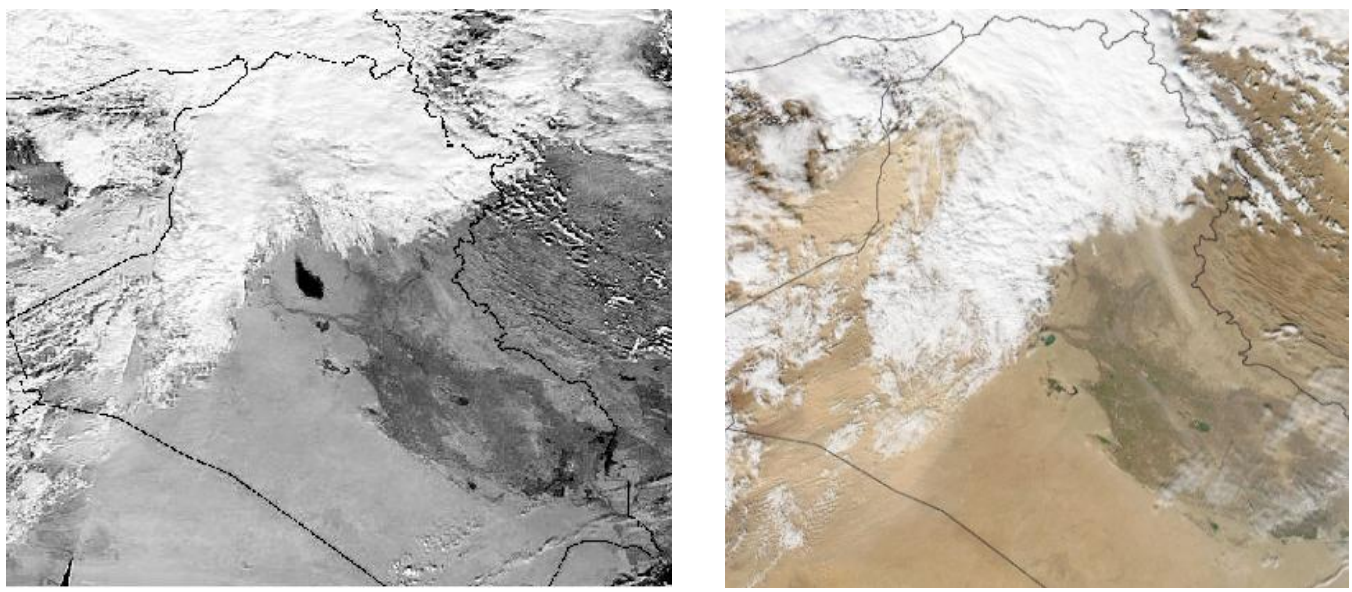

Fig. 2: Terra Modis satellite images (white and black, visible).

The visible satellite imagery is a high resolution image. This help us to see small-scale clouds features that aid the cloud identification like the brightness and the texture, or whether they are smooth or fibrous also the edge of clouds like fuzzy or sharp and the size, individual shapes, and the patterns such as linear or banded, circular or cellular.

The visible images representative of how much sunlight reflects from the surface of the earth and clouds back to the space. Thick clouds have a high albedo and show up brighter in the satellite images, also thin cirrus clouds have low albedos and are usually semitransparent to sunlight. While the clouds of free land and water surface will be dark, in that way convective clouds look brighter than stratiform clouds because it is thicker and contain more water droplets. In other words the clouds with lower level look brighter

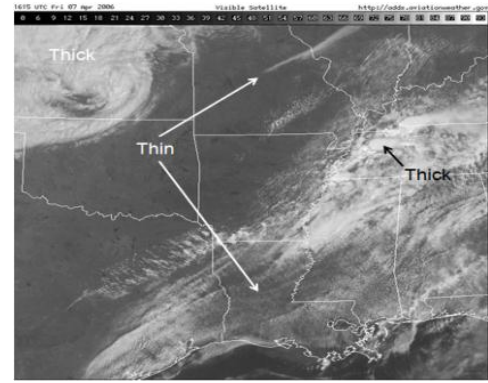

a than high level clouds that helps to determine cloud types and their altitude besides many cloud features. however visible satellite images unable to determine the temperature of clouds, so clouds determination whether they are rainy or not, is not applicable, and in some cases cirrus clouds are thin so the middle and low clouds can underlying it, so it may be seen through. The reflection from underlying clouds is added and cirrus clouds will look brighter. Also Visible images can only be made during sunlight hours, because it depend on the sunlight reflection from the clouds and surface of the earth, show Figs. 3 and 4.

Thin clouds

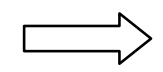

gray

Thick, dense clouds $\square$ bright white

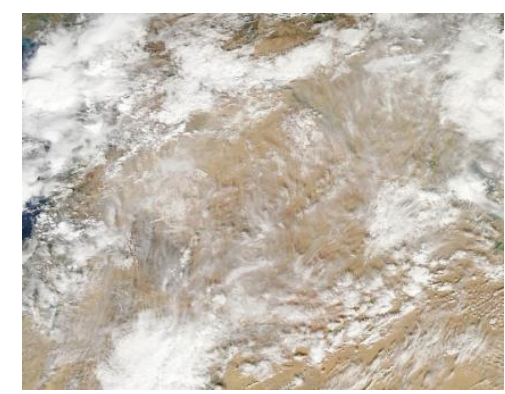

b

Fig.3: a) GEOS satellite image. b) MODIS true color visible satellite image in Baghdad. 

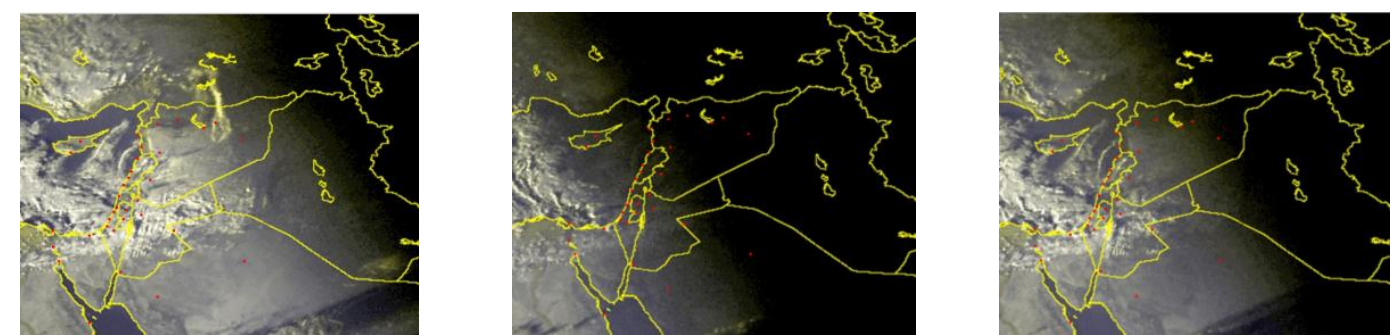

Fig. 4: Goes visible satellite images taken over Iraq in 18/12/2016 at 17:15, 17:30 and $17: 45 \mathrm{pm}$.

\subsection{Detect clouds by infrared satellite images (Estimating temperature)}

These images are heat based radiation from the infrared spectrum when surface is warm, it will emits more infrared radiations. For the satellite images, the cold surface seems bright and warm surface appears dark. Since the atmosphere cools as the altitude increase, high clouds will show up white and low clouds will be grayer, this will allow knowing the temperature. For cloud lighter areas of cloud show where the cloud tops are cooler and therefore where weather features like fronts and showing clouds, thus, stratiform clouds are brighter than convective clouds, the infrared images can view 24 hour a day, but also low clouds have the same temperature of the ground this will make it less discernible especially fog, that is way the visible images used to detect fog because of its show the sharp edge of fog because of terrain, show Figs. 5, 6, 7.

- Bright white $\rightarrow$ very cold temperatures $\rightarrow$ high clouds

- Black $\rightarrow$ very warm temperatures $\rightarrow$ low clouds or surface

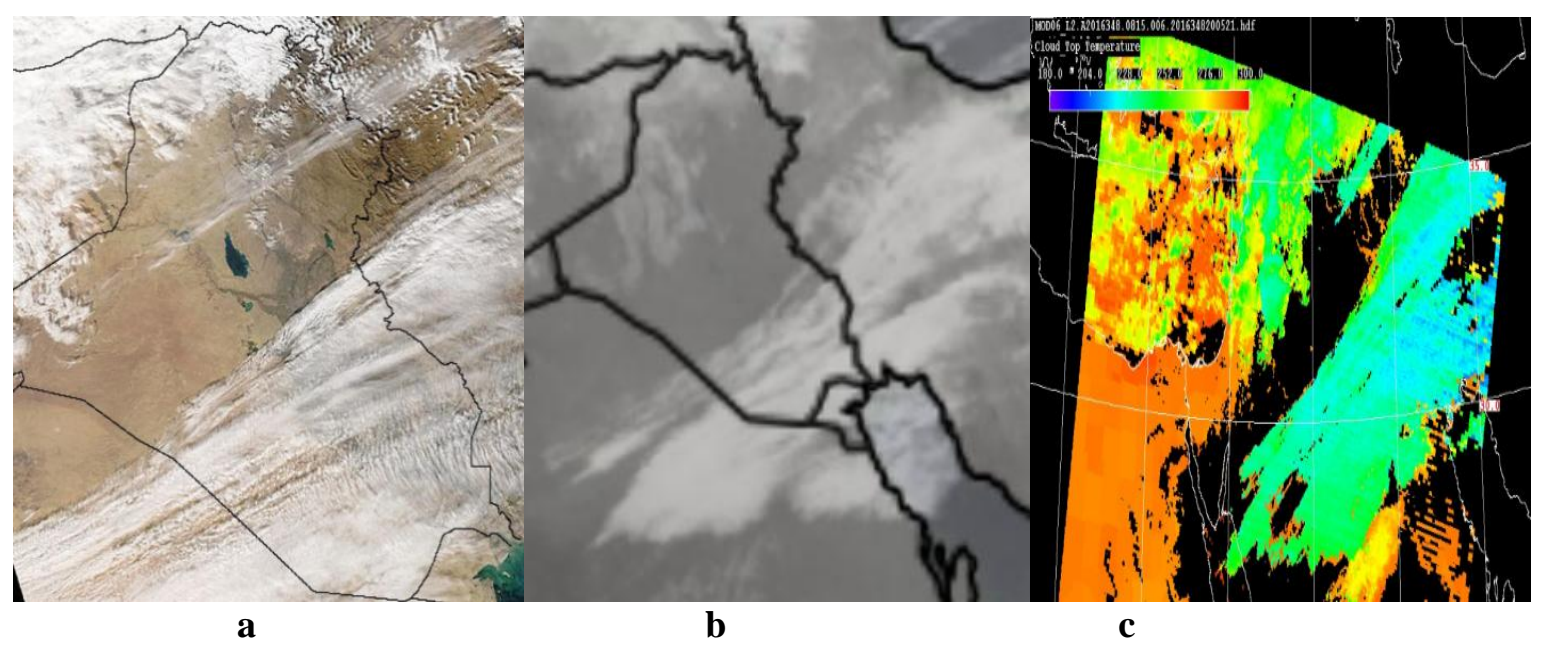

Fig. 5: a. Visible terra Modis satellite image over Iraq in 13/12/2016, b. infrared satellite image taken by goes satellite, $c$. Modis cloud top temperature mask band (31, 32). 


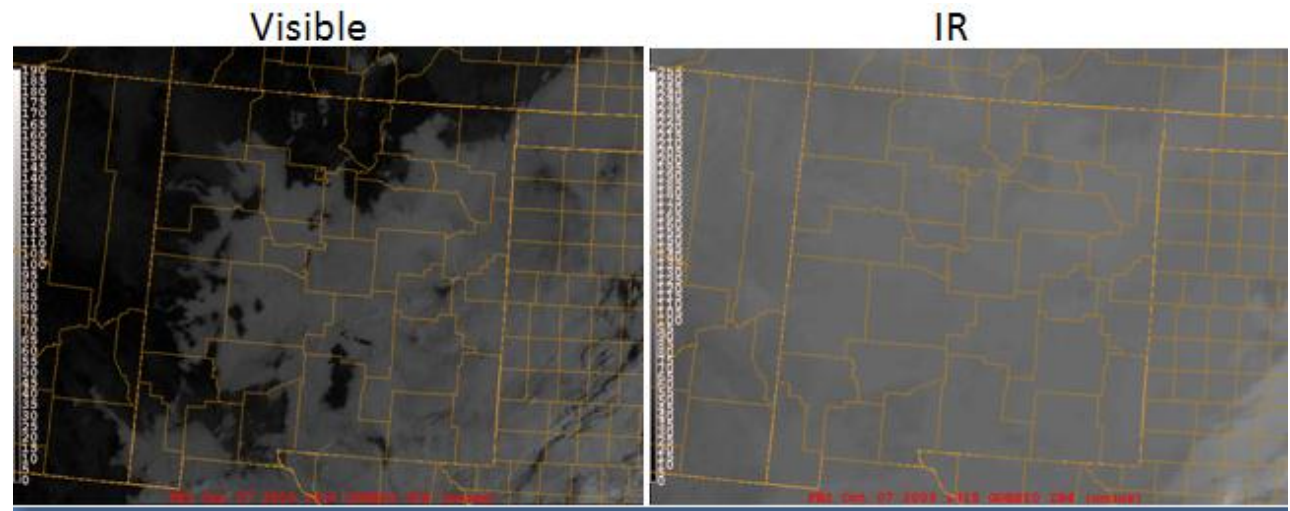

Fig. 6: The difference between visible and infrared satellite image in detecting fog taken by goes $4 \mathrm{~km}$ resolution.

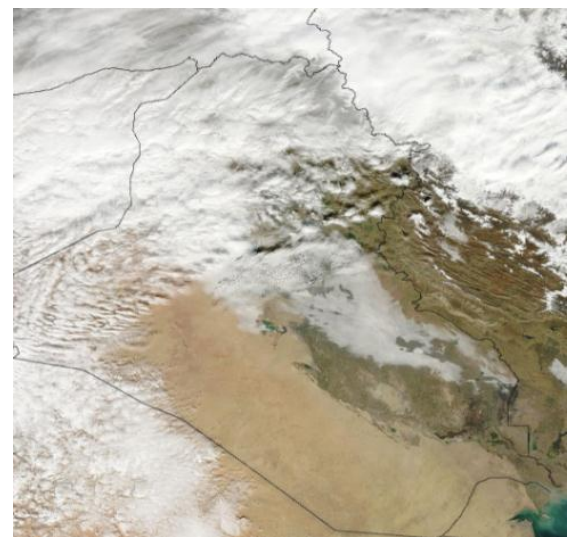

Fig. 7: Fog over Baghdad in 17/12/2015 detect by terra MODIS satellite as can be seen fog take the shape of terrain.

\section{Detect clouds by water vapor images}

This imagery represents a special kind of infrared measurement which measures the temperature of clouds and water vapor in a layer of the atmosphere about 6-10 $\mathrm{km}$ above the surface, such imagery highlights the presence of water vapor in the upper level of the atmosphere, this indicate the presence of moisture, this images don't give information about clouds but about how much water vapor in high levels. The most useful information from the water vapor images is location of storms and jet streams, also the high clouds. In water vapor satellite images, dark colors represent dry regions, while bright color represent high moisture regions, show Fig. 8.

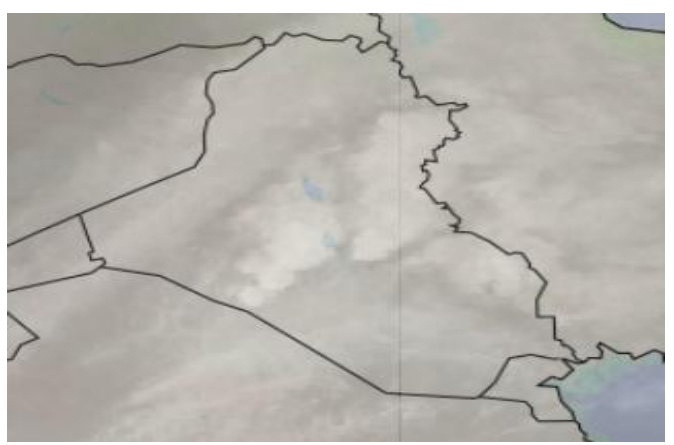

Fig. 8: Water vapor satellite image for Iraq in 24/12/2016, the dark color represent no moisture and bright color represent the region of high moisture. 
5. Infrared images and visible images

The best information is gained by using both the infrared and visible images to identify the cloud types and whether they are rainy or not. Table 4 below will help to determine the various types of clouds.

Table 4: Identify the cloud types from color both visible and infrared satellite images.

\begin{tabular}{|c|c|c|}
\hline IF CLOUDS ARE & $\begin{array}{c}\text { VISIBLE IMAGE } \\
\text { AND IF CLOUDS } \\
\text { APPEAR }\end{array}$ & POSSIBLE CLOUD TYPE \\
\hline cold & THICK(WHITE) & Cb OR Nimbostratus \\
\hline cold & Thin (gray) & cirrus \\
\hline warm & Thick(white) & Low stratus, fog \\
\hline warm & Thin(gray) & Cumulus, stratocumulus \\
\hline
\end{tabular}

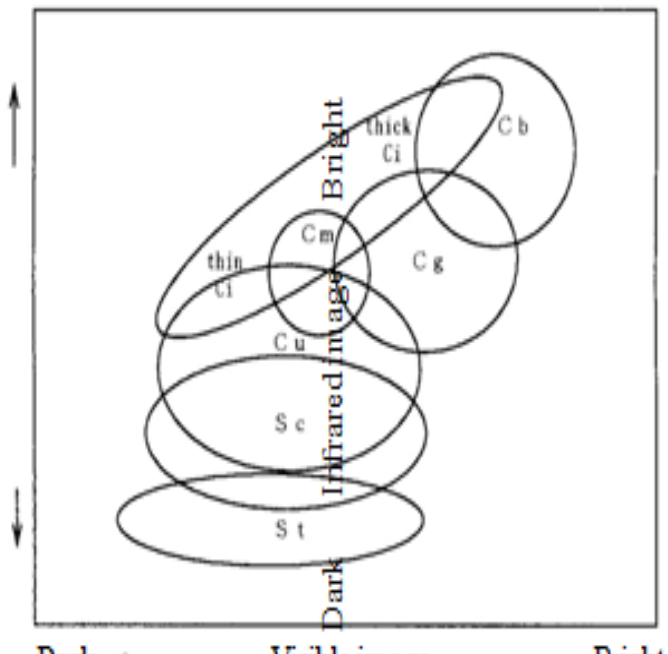

Dark $\longleftarrow \quad$ Visible image $\quad \longrightarrow$ Bright

a

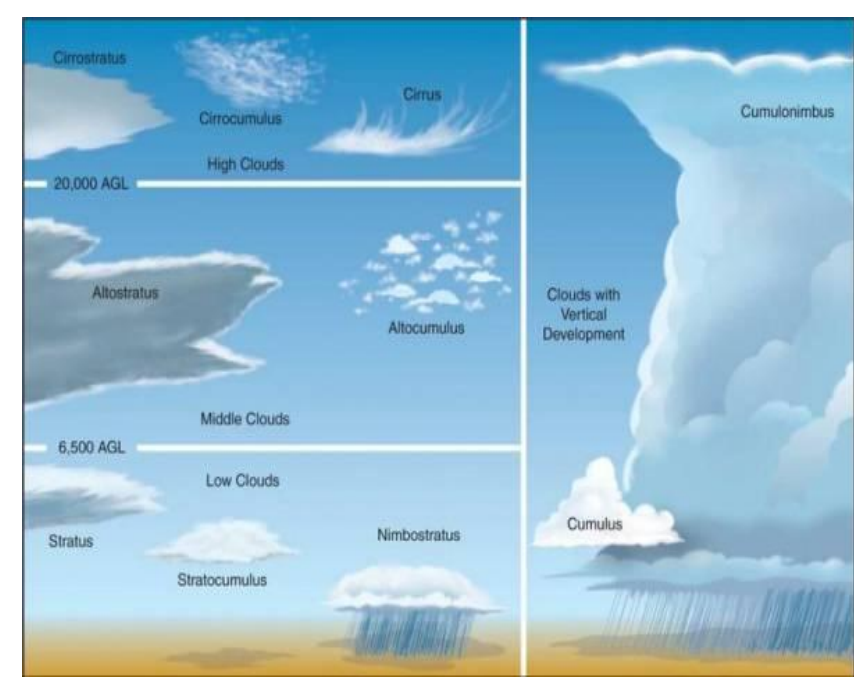

b

Fig. 9: a) Represent the brightness and darkness of clouds that appears in visible and infrared satellite images. b) represent which clouds are rainy [6]. 


\section{Interpretation study area clouds}

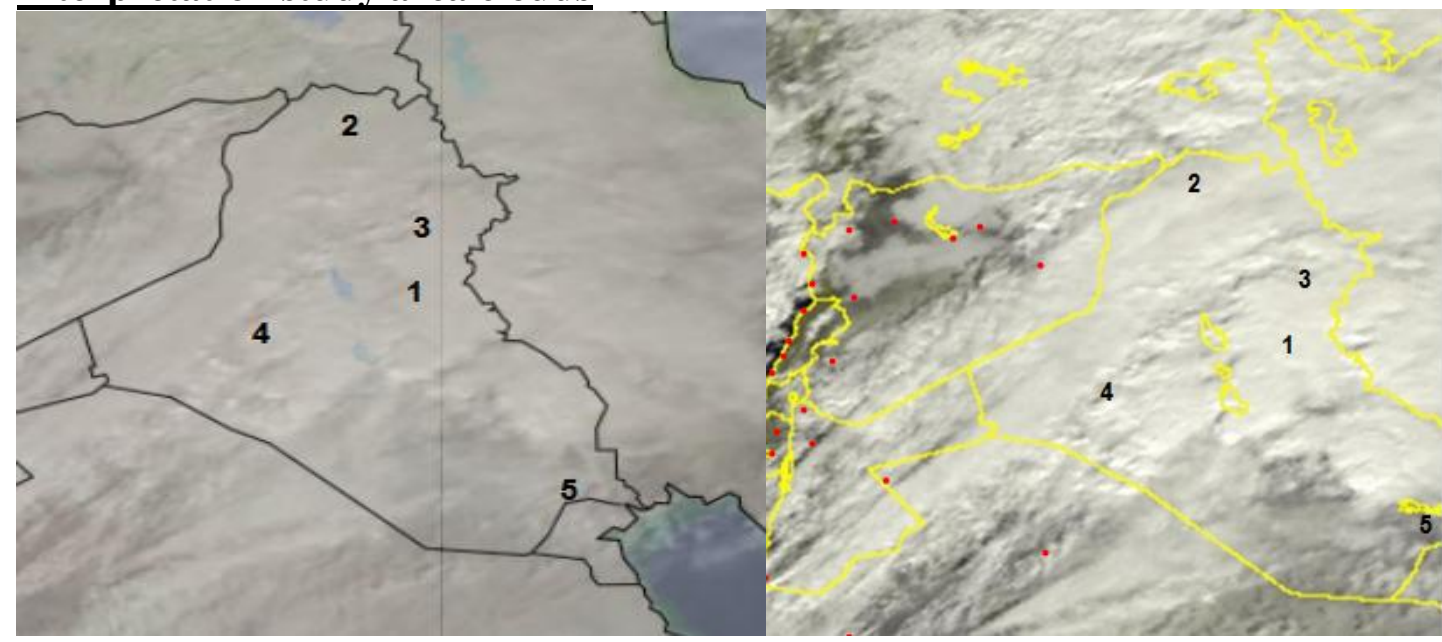

a

$\mathrm{b}$

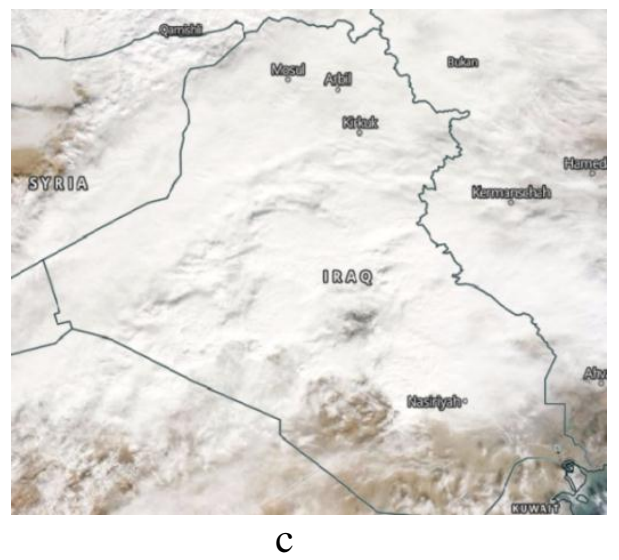

Fig. 10: a) Grayscale visible goes satellite image, b): grayscale visible METEOSAT satellite image, $c$ ): true color terra MODIS visible satellite image.

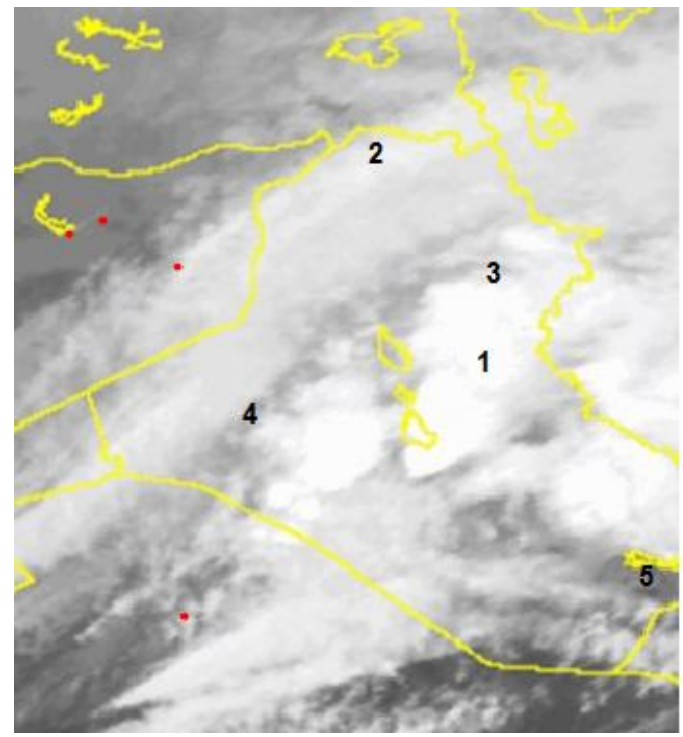

a

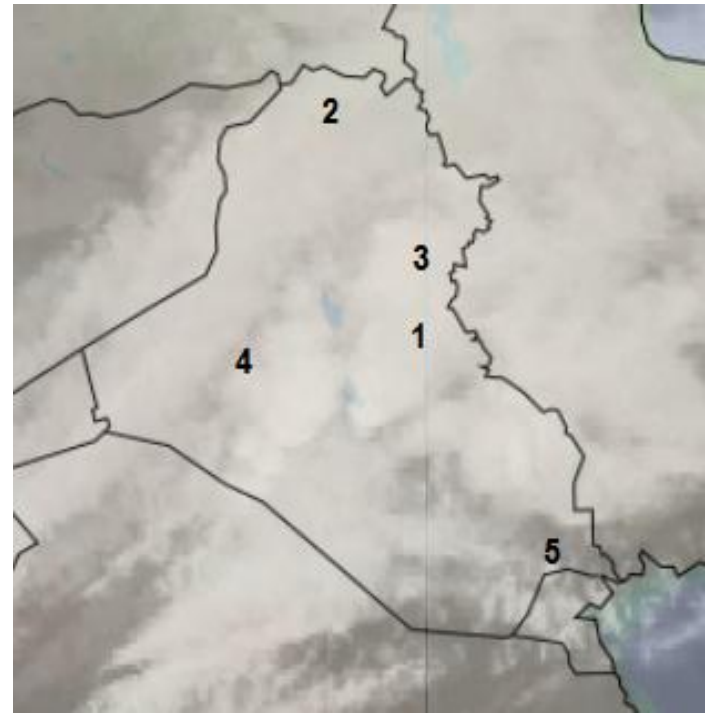

b

Fig. 11: a) Infrared meteosat satellite image, b): Infrared goes satellite image. 
The $\mathrm{Cb}$ (cumulonimbus) type of cloud is located at the cloud area 1 over Baghdad by the visible image which it looks thick and bright white and a wide band of cloud, on the infrared image its looks bright white. As can be seen from the weather forecast for Baghdad in 24/12/2016, show Table 5.

Table 5: Surface weather forecast for Baghdad.

\begin{tabular}{|cc|c|}
\hline Local Time 12:00 GMT=15:00 & Cloud Cover (eights) and Cloud Base \\
\hline $2016-12-24$ & $15: 00$ & $300-600 \mathrm{~m} \mathrm{8/8} \mathrm{8/8} \mathrm{cb} \mathrm{---}$ \\
\hline $2016-12-24$ & $12: 00$ & $300-600 \mathrm{~m} \mathrm{8/8} \mathrm{8/8} \mathrm{cb} \mathrm{---}$ \\
\hline $2016-12-24$ & $09: 00$ & $600-1000 \mathrm{~m} \mathrm{8/8} \mathrm{8/8} \mathrm{cu} \mathrm{---}$ \\
\hline
\end{tabular}

Above Duhok the cloud of region 2 are (Ns) cloud type from the visible image that looks medium to bright gray and a wide band of cloud, while the infrared image is medium gray to white as can be seen from the surface weather forecast for Duhok in 24/12/2016, show Table 6.

Table 6: The weather forecast for Duhok.

\begin{tabular}{|c|c|}
\hline 2016-12-24 15:00 & $600-1000 \mathrm{~m} \mathrm{8} / 87 / 8$ St Ns- \\
\hline $2016-12-24 \quad 12: 00$ & $600-1000 \mathrm{~m} 8 / 8$ 6/8 St Ns- \\
\hline 2016-12-24 09:00 & $600-1000 \mathrm{~m} 8 / 8$ 6/8 St Ns- \\
\hline
\end{tabular}

The cloud area 3, the cloud types over Kirkuk is $\mathrm{Cu}$, in the visible image it looks Light gray to white and a wide band of cloud, and then the infrared image its look Medium to light gray. As can be seen from the weather forecast in Kirkuk in 24/12/2016, show Table 7.

Table 7: Surface weather forecast for Kirkuk.

\begin{tabular}{|cc|c|}
\hline \multicolumn{2}{|c|}{ Local Time } & Cloud Cover (eights) \\
12:00 GMT & $=15: 00$ & And Cloud Base \\
\hline $2016-12-24$ & $15: 00$ & $600-1000 \mathrm{~m} 8 / 88 / 8 \mathrm{Cu}--$ \\
\hline $2016-12-24$ & $12: 00$ & $600-1000 \mathrm{~m} 8 / 84 / 8 \mathrm{St} \mathrm{Ns} \mathrm{Cs}$ \\
\hline $2016-12-24$ & $09: 00$ & $600-1000 \mathrm{~m} 8 / 88 / 8 \mathrm{Cu}--$ \\
\hline
\end{tabular}

In the visible image shows the $(\mathrm{Cu})$ cloud type that is located in the cloud area 4, which has the characteristics such as Light gray to white cloud, and the infrared image, gives Medium to light gray cloud. As can be seen from the weather forecast for Haditha in 24/12/2016, show Table 8.

Table 8: Surface weather forecast for Haditha.

\begin{tabular}{|c|c|}
\hline $\begin{array}{c}\text { Local Time } \\
12: 00 \text { GMT }=15: 00\end{array}$ & $\begin{array}{l}\text { Cloud Cover (eights) } \\
\text { And Cloud Base }\end{array}$ \\
\hline 2016-12-24 15:00 & $1000-1500 \mathrm{~m} 8 / 8 \mathrm{8} / 8 \mathrm{Cu}--$ \\
\hline 2016-12-24 12:00 & $1000-1500 \mathrm{~m} 8 / 8 \mathrm{8} / 8 \mathrm{Cu}--$ \\
\hline 2016-12-24 09:00 & $600-1000 \mathrm{~m} 8 / 8 \mathrm{8} / 8 \mathrm{Cu}--$ \\
\hline
\end{tabular}

The altocumulus cloud type over Basra is located in the cloud area 5, that is identified by the visible image, which looks like thin, medium to light gray cloud, and the appearance of cloud as Medium gray by the infrared image. As can be seen from the weather forecast for Basra in 24/12/2016, show Table 9. 
Table 9: Surface weather forecast for Basra.

\begin{tabular}{|c|cc|c|c|c|c|c|}
\hline \multicolumn{2}{|c|}{ Local Time } & Cloud Base & \multicolumn{2}{|c|}{ Cloud Cover } & \multicolumn{3}{c|}{ Genus } \\
\cline { 4 - 8 } 12:00 GMT =15:00 & & total & low & low & middle & high \\
\hline $2016-12-24$ & $15: 00$ & $>\begin{array}{c}2500 \\
m\end{array}$ & $5 / 8$ & $3 / 8$ & - & Ac & $\mathrm{Ci}$ \\
\hline $2016-12-24$ & $09: 00$ & $>\begin{array}{c}2500 \\
m\end{array}$ & $5 / 8$ & $0 / 8$ & - & - & $\mathrm{Ci}$ \\
\hline $2016-12-24$ & $03: 00$ & - & $0 / 8$ & $0 / 8$ & - & - & - \\
\hline
\end{tabular}

Interpretation the terra MODIS atmospheric product technique

MODIS atmospheric products provides full details about clouds using different bands (visible, near infrared and short waves infrared bands), terra MODIS instrument imagery in 36 different bands $(0.4 \mu \mathrm{m}$ to $14.4 \mu \mathrm{m})$. These bands have spatial resolution of ( $2 \mathrm{~km}, 1 \mathrm{~km}, 250 \mathrm{~m})$. MODIS provides images for Iraq at least two images a day. The atmospheric products of MODIS show the clouds top temperature, cloud top pressure, cloud optical thickness, cirrus reflectance, cloud fraction, cloud effective radius and multi-layer clouds. Each one of these gives information on the type of clouds. The MODIS Cloud Top Temperature layer indicates the atmospheric temperature at the top of the clouds measured in Kelvin $(\mathrm{K})$. Clouds can contain ice or water and

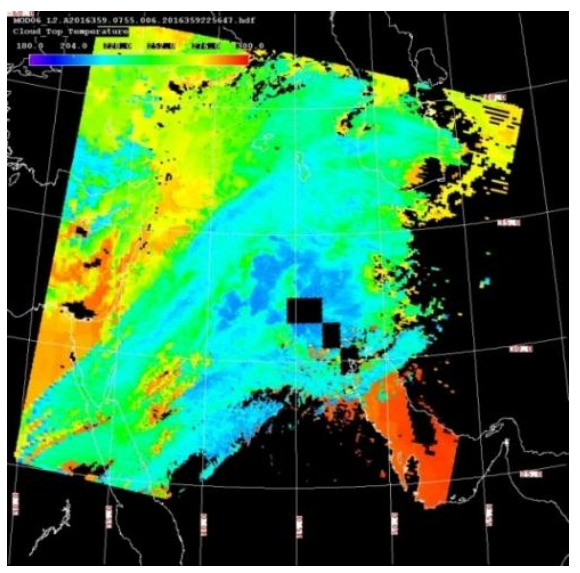

a each will react differently. Knowing the temperature of the cloud (weather a cold, icy cloud, or a warmer, wet cloud) and the changes in the cloud phase can provide information on the height and type of clouds. The MODIS Cloud Top Pressure layer indicates the pressure at the top of the clouds measured in hectopascal (hPa). Cloud Top Pressure gives information about the highest altitude the cloud, and the layer is useful for identifying convective clouds - tall clouds that produce thunderstorms. Generally, altitude increase as the pressure decrease so, if the pressure low then the cloud is tall. The cloud top temperature top pressure and heights indicates that clouds are cold and high, the estimated height for most clouds are $12000 \mathrm{~m}(12 \mathrm{~km})$ as shown in Figs. 12 and 13.

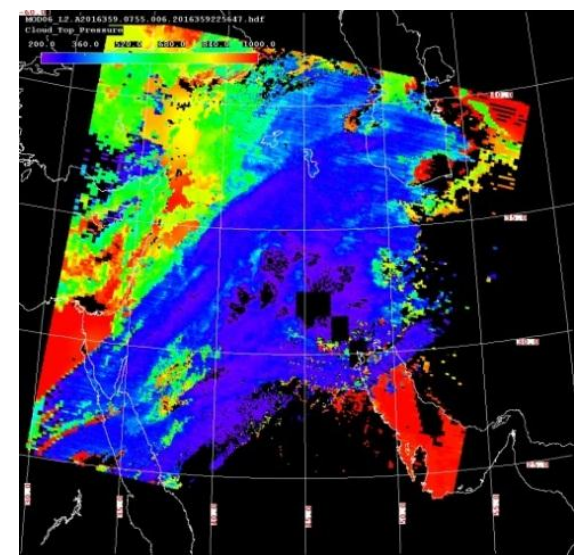

$\mathrm{b}$

Fig. 12: a) Cloud top pressure in blue color over most of Iraq cities which is (200 360) hpa (hectopascal), b) represent clouds top temperature in light blue and cyan (180 228) Kelvin. 


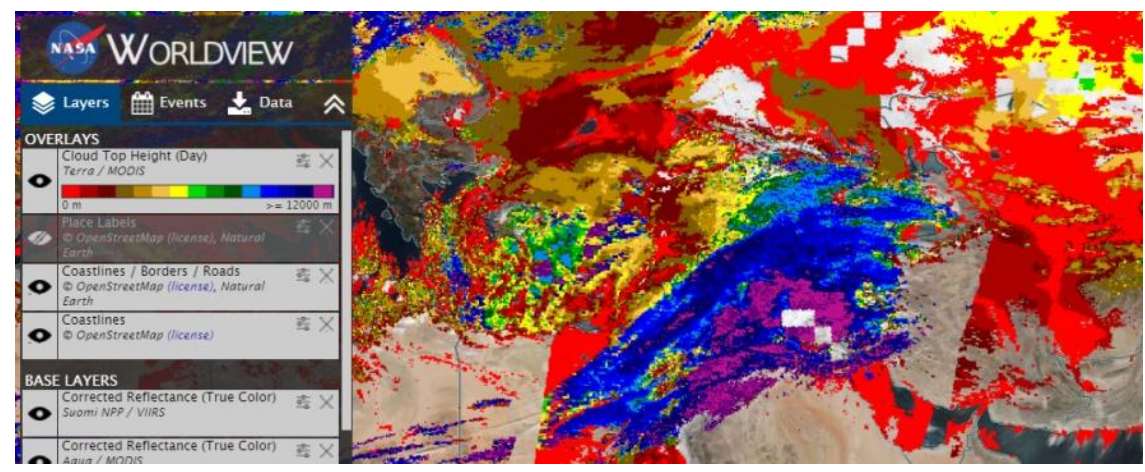

Fig.13: Indicate the height of cloud in purple color over middle and most of south Iraq (12000 m) height.

The MODIS Cloud Optical Thickness layer is a measure of the amount of sunlight affected by absorption and scattering when passing through the clouds. Clouds scatter and reflect most visible light. Hence it is simultaneously retrieved with Cloud Effective Radius by simultaneously measuring the reflection function of a non-absorbing and absorbing spectral channel (Visible/Near Infrared) (VNIR) and Shortwave Infrared (SWIR), respectively) and comparing the resulting measurements with theoretical forward model calculations. The MODIS Cloud Effective Radius layer is a measure of cloud particle size in microns $(\mu \mathrm{m})$. It is retrieved globally during day time for liquid and ice phases. It is simultaneously retrieved with Cloud Optical Thickness by simultaneously measuring the reflection function of a non-absorbing and absorbing spectral channel (Visible/Near Infrared (VIS/NIR) and Shortwave Infrared (SWIR), respectively) and comparing the resulting measurements with theoretical forward model calculations. Generally, smaller the particle size, brighter and more reflective is the clouds. The smaller cloud particles tend to reflect and scatter more sunlight back into space. The MODIS Cloud Fraction is a measure of the percentage of Earth's surface covered by clouds. Cloud Fraction is important in determining the amount of sunlight that reaches the Earth's surface, the amount of sunlight reflected back into space, and the amount of heat escaping from the surface and atmosphere back into space. Clouds play a very important role in the Earth's energy budget and climate system. The MODIS Cloud Fraction layer indicates the fraction of pixels within a 25 square kilometer box $(5 \mathrm{x} 51 \mathrm{~km}$ pixels) that are determined to be confident or probably cloudy by the MOD/MYD $351 \mathrm{~km}$ x $1 \mathrm{~km}$ Cloud Mask. The MODIS Water Vapor layer shows the total amount of water vapor in a $5 \mathrm{~km}$ by $5 \mathrm{~km}$ column of the atmosphere, measured in centimeters (cm). Water cycles through the earth's atmosphere in three states: solid (ice), liquid (rain drops), gas (water vapor). Monitoring water vapor is useful as it influences weather patterns.

The cloud optical thickness, effective radius, water vapor and cloud fraction indicates that's cloud are thick, evaporate and large clouds (convective clouds) as shown in Fig. 14. 


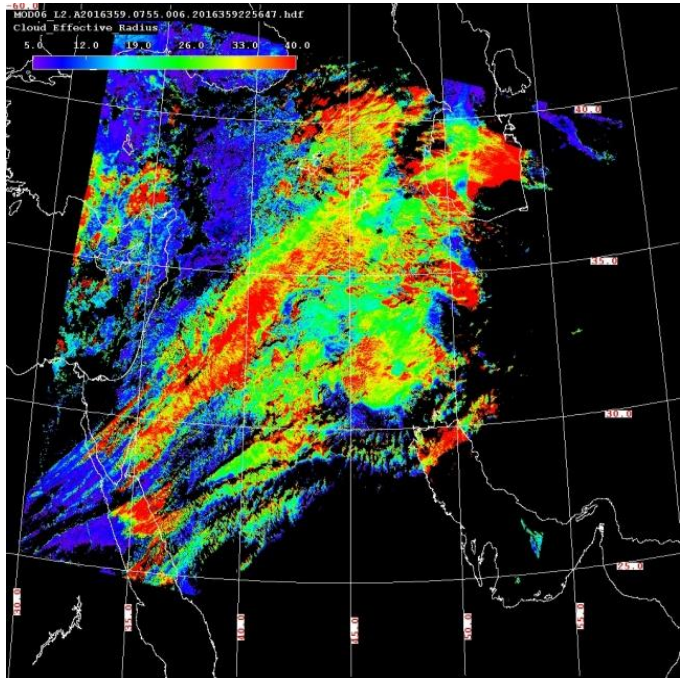

(a)

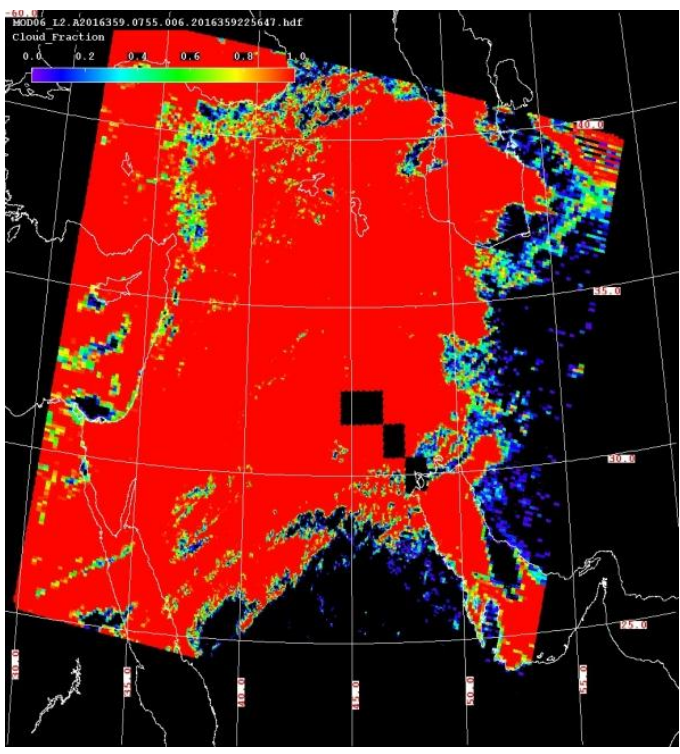

(b)

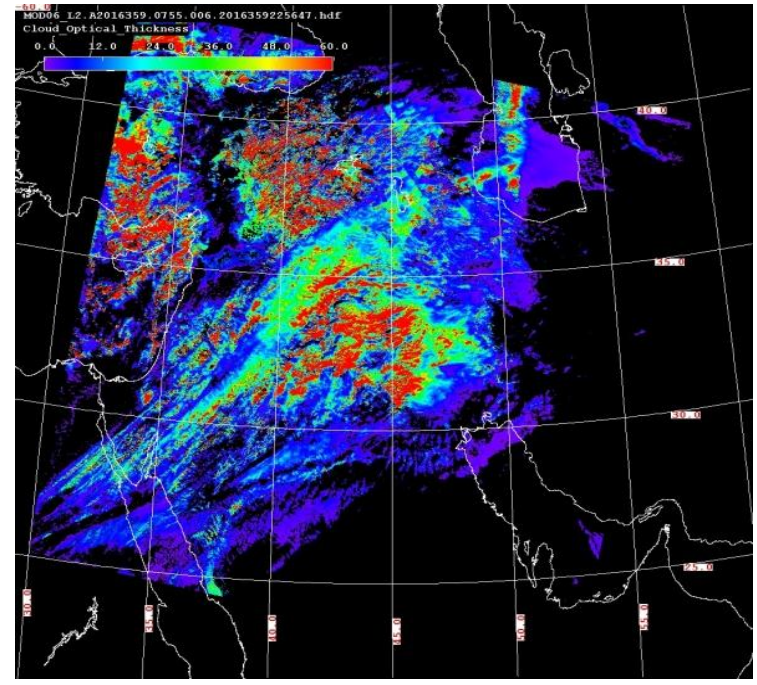

(b)

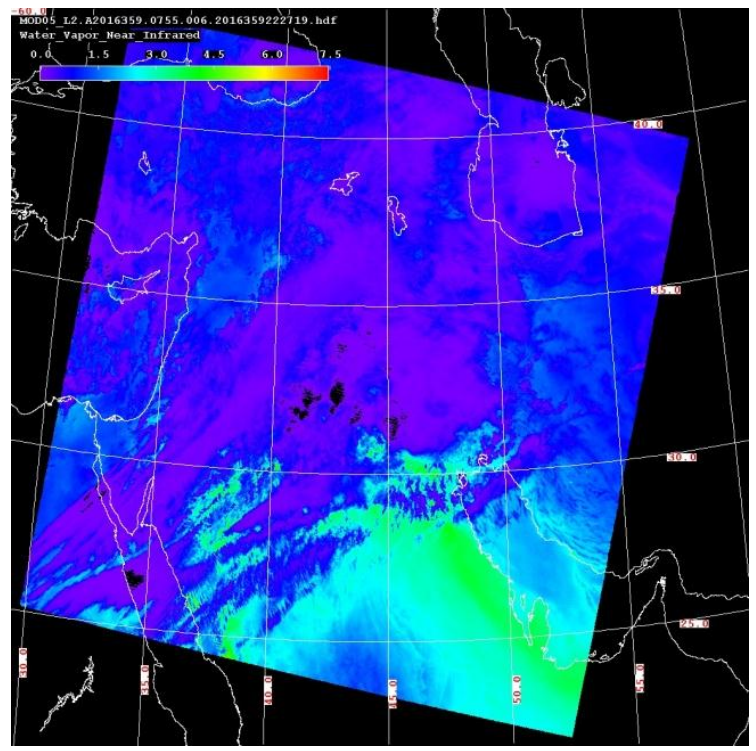

(d)

Fig. 14: a) Illustration, cloud effective radius, b) the thickness of clouds in both layers band $7(2.1 \mu \mathrm{m})$ were used, $c)$ represent the cloud fraction, $d)$ show how much water vapor over Iraq.

From the terra atmospheric products one can conclude that cloud over Iraq especially over Baghdad are cold, high, large, evaporate and thick (convective clouds), after comparing between the result of this technique with the (visible and infrared satellite images method), one can see the results are the same which indicate the precise and accurate of the method.

\section{Conclusion}

1- The dark cloud color in visible image is thin cloud, while bright white visible image is thick clouds.

2- The dark cloud color in infrared imagery is warm clouds (low cloud), while bright color is a cold cloud (high cloud).

3- The dark color in a water vapor image indicates regions with low 
moisture, while bright color represents regions with moisture.

4- Fog is hard to detect by infrared images and the infrared images will detect the temperature from both ground and low cloud.

5- Finding many cloud types over Iraq and other regions, detect by both infrared and visible satellite images, chart in table 10 represents the clouds types and how they look like in both infrared and visible satellite images.

6- The results from the (the terra modis atmospheric products technique) are the same for the using of (visible and infrared satellite images method) which is cold, high, large, evaporate and thick (convective cloud), this indicate the precise and accurate of the method.

Table 10: The brightness of the clouds in visible and infrared satellite images.

\begin{tabular}{|c|c|c|c|c|c|}
\hline Cloud type & Content & $\begin{array}{l}\text { Base height } \\
\text { above } \\
\text { ground }\end{array}$ & $\begin{array}{c}\text { Characteristic } \\
\text { shape on satellite } \\
\text { image }\end{array}$ & $\begin{array}{c}\text { Color or tone } \\
\text { visible satellite }\end{array}$ & $\begin{array}{c}\text { Color or tone IR } \\
\text { satellite }\end{array}$ \\
\hline Cirrus & Ice & $\begin{array}{l}20000 \text { to } \\
40000 \mathrm{ft}\end{array}$ & $\begin{array}{l}\text { Thin wispy or } \\
\text { smooth ground } \\
\text { usually visible }\end{array}$ & $\begin{array}{l}\text { Light gray or } \\
\text { white but thin }\end{array}$ & White \\
\hline Cirrostratus & Ice & $\begin{array}{l}15000 \text { to } \\
30000 \mathrm{ft}\end{array}$ & $\begin{array}{c}\text { Thin veil or sheet } \\
\text { like }\end{array}$ & $\begin{array}{l}\text { Light gray or } \\
\text { white }\end{array}$ & Light gray or white \\
\hline Cirrocumulus & Ice & $\begin{array}{l}15000 \text { to } \\
30000 \mathrm{ft}\end{array}$ & Thin patches & $\begin{array}{c}\text { Light gray or } \\
\text { white }\end{array}$ & Light gray or white \\
\hline Altostratus & $\begin{array}{l}\text { Water and } \\
\text { ice }\end{array}$ & $\begin{array}{l}6500 \text { to } \\
15000 \mathrm{ft}\end{array}$ & $\begin{array}{c}\text { Smooth layered } \\
\text { cloud but edges } \\
\text { maybe ragged }\end{array}$ & $\begin{array}{l}\text { Medium to light } \\
\text { gray }\end{array}$ & Medium gray \\
\hline Altocumulus & $\begin{array}{l}\text { Water and } \\
\text { ice }\end{array}$ & $\begin{array}{l}6500 \text { to } \\
15000 \mathrm{ft}\end{array}$ & $\begin{array}{l}\text { Smooth layered } \\
\text { cloud but edges } \\
\text { maybe ragged }\end{array}$ & $\begin{array}{l}\text { Medium to light } \\
\text { gray }\end{array}$ & Medium gray \\
\hline Stratocumulus & $\begin{array}{l}\text { Water(ice } \\
\text { in winter) }\end{array}$ & $\begin{array}{c}1500 \text { to } 6500 \\
\mathrm{ft}\end{array}$ & $\begin{array}{l}\text { Lumby/cellular } \\
\text { maybe in lines or } \\
\text { groups with edges } \\
\text { touching }\end{array}$ & $\begin{array}{l}\text { Medium to light } \\
\text { gray }\end{array}$ & $\begin{array}{l}\text { Dark to medium } \\
\text { gray .sometimes } \\
\text { poor contrast } \\
\text { between land and } \\
\text { cloud }\end{array}$ \\
\hline Cumulus & $\begin{array}{l}\text { Water may } \\
\text { have ice }\end{array}$ & $<6500 \mathrm{ft}$ & $\begin{array}{c}\text { Lumby/bumby } \\
\text { individual elements } \\
\text { visible }\end{array}$ & $\begin{array}{l}\text { Light gray to } \\
\text { white }\end{array}$ & $\begin{array}{l}\text { Medium to light } \\
\text { gray }\end{array}$ \\
\hline Cumulonimbus & $\begin{array}{l}\text { Water and } \\
\text { ice }\end{array}$ & $\begin{array}{l}<6500 \mathrm{ft} \text { but } \\
\text { tops can } \\
\text { grow to } \\
>50000 \mathrm{ft}\end{array}$ & $\begin{array}{l}\text { Globular or carrot } \\
\text { shaped bumby. } \\
\text { Maybe in lines and } \\
\text { cast shadows }\end{array}$ & Bright white & Bright white \\
\hline Nimbostratus & $\begin{array}{l}\text { Water and } \\
\text { ice }\end{array}$ & $\begin{array}{l}6500 \mathrm{ft} \text { or } \\
\text { less but } \\
\text { layered up to } \\
20000 \mathrm{ft}\end{array}$ & $\begin{array}{l}\text { Large area of } \\
\text { smooth clouds with } \\
\text { striations }\end{array}$ & $\begin{array}{l}\text { Medium to } \\
\text { bright gray }\end{array}$ & $\begin{array}{l}\text { Medium gray to } \\
\text { white }\end{array}$ \\
\hline $\begin{array}{l}\text { Stratus (and } \\
\text { fog) }\end{array}$ & $\begin{array}{l}\text { Water (and } \\
\text { ice in } \\
\text { winter) }\end{array}$ & $<3000 \mathrm{ft}$ & $\begin{array}{l}\text { Smooth.shaped } \\
\text { frequently defined } \\
\text { by topography }\end{array}$ & $\begin{array}{l}\text { Medium gray to } \\
\text { white depending } \\
\text { upon cloud } \\
\text { thickness }\end{array}$ & $\begin{array}{l}\text { Dark to medium. } \\
\text { Frequently poor } \\
\text { contrast between } \\
\text { cloud and use visible } \\
\text { to help when } \\
\text { available }\end{array}$ \\
\hline
\end{tabular}




\section{References}

[1] L. C. W. Bonacina, The

subsequent evaluation in WRF highGeographical Journal, 129, 2 Jun. (1963) 34-45.

[2] Ralph E. Huschke, Ed. "Glossary of Meteorology"

American

Meteorological Society, Boston, Mass. 638 pp. Vol. 131, Issue 3395, 22 Jan 1960 pp. 222.

[3] S. Srinivasan "Basic Cloud Computing" Types Chapter Cloud Computing Basics Part of the series Springer Briefs in Electrical and Computer Engineering, pp. 17-41 (15 May 2014).

[4] James R. Holton Reviewed by D. O. Staley, An American Journal of Physics 415 (July 2005) 23.

[5] G. Thompson, M. Tewari "Explicitly-coupled cloud physics and radiation parameterizations and resolution convective forecasts" University of Wisconsin-Madison, USA Volume 168, (1 February 2016), Pages 92-104.

[6] WMO. "International Cloud Atlas". Volume I: Manual on the observation of clouds and other meteors. WMO Publication (1975). (Vol. I, pp. 30-90). [7] K. J. Weston, Tellus, 32, 5 October (1980) 433-438.

[8] R. Field, Paul Journal of the Atmospheric Sciences, 56, 12 (1999) 13-17.

[9] Luis M. Vaquero ACM SIGCOMM Computer Communication Review, 39, 1, January (2009) 50-55. 